\title{
Die gebruik van die metafore in Psalm 80 (79 -LXX) in vergelyking met Johannes 15:1-8
}

J G van der Watt

(UP)

\section{ABSTRACT:}

The use of metaphors in Psalm 80 (79 -LXX) in comparison with John 15:1-8

The dynamics of metaphor, which are found in John 15:1-8, are compared with the dynamics of metaphor in Psalm 79 (LXX). This is done against the background of the dominance of the ancient Greek philosphical tradition in considering metaphors in ancient texts. It is shown that the dynamics of metaphor in John 15 and Psalm 79 (LXX) are based on the same characteristics. This implies that more care should be taken in identifying the roots of the dynamics of metaphor in ancient literature.

\section{INLEIDING}

Die gevierde Johanneskenner, C H Dodd, het opgemerk dat die beeldspraak in Johannes 15 "should be understood out of a rich background of associations which the vine-symbol had already acquired" 1 . Hiermee het hy natuurlik na die gebruik van die wingerdstok in onder andere die Ou Testament verwys ${ }^{2}$.

In hierdie artikel word 'n vergelyking gemaak tussen die metafoorgebruik $^{3}$ in 'n bekende Ou-Testamentiese gedeelte, naamlik Psalm 80 (LXX - 79), en 'n ewe bekende gedeelte, naamlik Johannes 15. In beide gedeeltes word 'n wingerdstok metafories benut ten einde 'n figuurlike beskrywing van fasette rondon die volk van God te gee. Die belang van die vergelyking lê daarin dat daar in die gebruik van metafore in die antieke dikwels in die rigting van Aristoteles ${ }^{4}$ gekyk word. $\mathrm{Hy}$ is die beroemdste, hoewel nie die enigste nie, antieke denker wat hom oor die gebruik van metafore uitlaat. Daar gaan egter aangetoon word dat wat funksioneel op metaforiese vlak in Psalm 80 (LXX - 79) aangetref word, feitlik identies is met wat in Johannes 15 gevind word. Die implikasie is dat die stuk Joodse literatuur dieselfde metaforiese dinamiek as Johannes 5 vertoon, wat gevolglik die vraag na hoe en waar hierdie dinamiek vandaan kom, opnuut open. 


\section{Psalm 80 (79-LXX)}

In Psalm 80 (79 - LXX) word 'n lied gesing waarin daar gevra word vir herstel en verlossing in die lig van 'n vernietigende bedreiging. Hierdie psalm gaan waarskynlik oor die noordelike stamme wat in ballingskap weggevoer is deur die Assiriërs (2 Kon 15:29; 17:5-6). Dit lyk egter of daar druk op die Suidryk ook is (vse 2-3). Dit het in die agste eeu voor Christus (732-721 vC) afgespeel ${ }^{6}$. Tog is hier ook tekens van bure wat teen Israel veg (vs 7).

Die middelste gedeelte $(80: 7-16)$ bevat die beeld van 'n wingerdstok wat geplant is en goed gegroei het, maar tog nou vernietig is. Dit is waarskynlik 'n refleksie van die geskiedkundige verloop wat bo genoem is. In die narratief word die wingerdstokbeeld metafories benut as uitdrukking van wat konkreet met Israel gebeur het.

'n Kort uiteensetting van die funksionele wyșe waarop dit gedoen word, bied interessante resultate. Wat vervolgens weergegee word, is die teks van Psalm 79:9-18 (LXX) met 'n vrye vertaling. Daarna sal daar enkele interpretatiewe opmerkings gemaak word:

\section{LXX:}

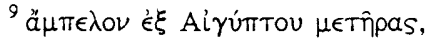

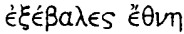

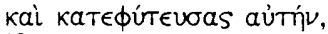

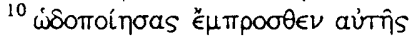

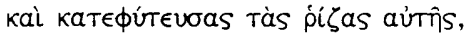
kaì $\dot{\epsilon} \pi \lambda \dot{r} \sigma \theta \eta \dot{\eta} \gamma \hat{\eta}$.

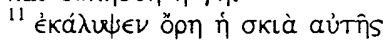

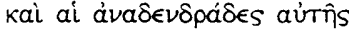

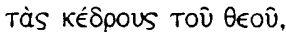

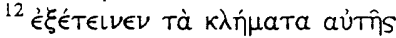

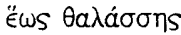

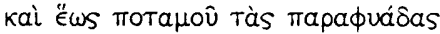
aưTîs.

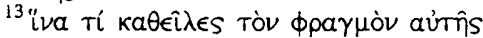

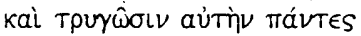

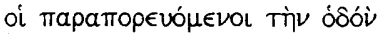

${ }^{14}$ é $\lambda$ un

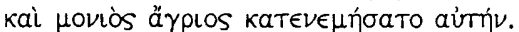

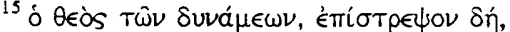

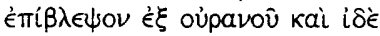

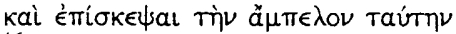

${ }^{16}$ kà katáptıoal aưrtív,

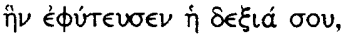

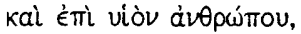

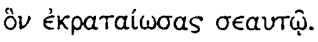

(Vrye) vertaling:

U het die wynstok uit Egipte verwyder, $\mathrm{U}$ het die nasies uitgegooi en $U$ het dit geplant, U het plek daarvoor gemaak en die wortels geplant en die aarde is toegegroei.

Sy skaduwee net die berge bedek en sy takke het teen die seders van God opgerank.

Dit het sy takke uitgestoot tot by die see

en sy sytakke tot by die rivier

Waarom het U sy muur afgebreek?

sodat almal daarvan insamel

wat daarlangs verbystap?

Wildevarke uit die bos verniel dit en wilde diere van die veld eet daarvan.

God van die magte, draai tog na ons toe.

Kyk af van die hemel af en kyk.

Kyk asseblief agter die wingerdstok.

Hou die wingerdstok reg

wat $\mathrm{U}$ met $\mathrm{u}$ regterhand geplant het.

Kyk agter die seun van die mens (menslike seun)

wat $U$ vir Useif sterk gemaak het. 


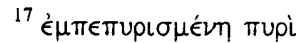

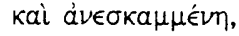

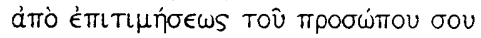

a่moגoûvTal.

${ }^{18} \gamma \in \nu \eta \eta \dot{\theta} T \omega \dot{\eta} x \in i ́ \rho$ бov

$\epsilon \pi^{\prime} a ̊ k \delta \rho \alpha \delta \epsilon \xi t a ̂ s$ oov

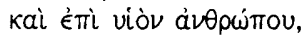

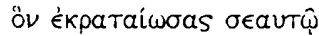

Die wingerdstok is met vuur verbrand

en is opgespit.

Hulle sal vergaan voor $u$

bestraffing.

Laat $u$ hand rus

op die man aan $u$ regterhand

en op die seun van die mens

wat $\mathrm{u}$ vir Uself sterk gemaak het.

Heelwat oorenkomste bestaan tussen die metaforiese dinamiek van Psalm 79 ( $\mathrm{LXX})$ en Johannes 15. Die volgende is nie 'n volledige gedetaileerde bespreking nie, maar wil die alleen die ooreenkomste illustratief aanstip.

\section{METAFORE VAN SUBSTITUSIE}

In Psalm 79 (LXX) word metafore aangetref wat op die basis van substitusie funksioneer. "Substitusie" impliseer dat 'n letterlike woord in die metafoor met 'n figuurlike woord vervang word wat dan as basis dien vir die analogie wat volg. Dit moet nie net verstaan word as meganiese substitusie alleen nie, maar soms laat personifikasie wedersydse beïnvloeding tussen die twee objekte toe. Verskeie grade van "substitusie" kan dus onderskei word, afhangende van die literêre situasie?

Voorbeelde van "substitusie" uit Psalm 79 (LXX) is onder andere Israel, of die seun (vers 16), wat met "wingerdstok" vervang word. Die seun is ook ' $\mathrm{n}$ ingebedde metafoor vir Israel ${ }^{8}$. God word met tuinier vervang, hoewel dit ook ' $n$ ingebedde metafoor is. Deur Israel met die wingerdstok te vervang maak die verdere beeld moontlik van die ranke wat oor die berge en tot by die see sprei asook die ranke wat verbrand of uitgegrawe word. Die "vehicle" 9 vir "wildediere/varke" word nie direk in die konteks benoem nie, wat dit 'n gesuspendeerde metafoor ${ }^{10}$ maak. Op die wyse word 'n metafoorring daargestel. Verskeie metafore funksioneer saam om ' $n$ netwerk te vorm ten einde 'n meer uitgebreide beeld daar te stel. Die leser sien dus 'n tuinier en wingerd met wilde diere wat die wingerd bedreig en so meer. Hierdie konkrete beeld met sy verskeidenheid objekte word via substitusie representatief van die belangrike "objekte" wat op geestelike vlak 'n rol speel. Die aandag word so gevestig op twee realiteite (die konkrete en die figuurlike) wat op een of ander wyse met mekaar verband hou. Die aardse werklikheid word dus representatief vir 'n geestelike werklikheid waaroor die skrywer dit eintlik het. Skematies kan dit so voorgestel word ${ }^{11}$ : 


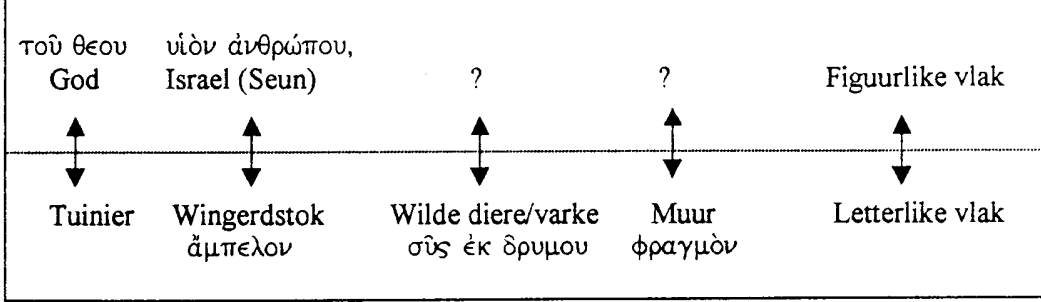

Dieselfde tegniek van substitusie word in die ontvouing van die wingerdstokbeeld in Johannes 15 aangetref. Die letterlike en figuurlike vlakke loop parallel wat die relevante objekte betref. Met behulp van substitusie word die objekte soos wingerdstok, tuinier en takke asook die relasie tussen hierdie objekte onderling verbind met 'n geestelike realiteit waarin die Vader, Jesus en dissipels die bepalende rol speel. Dit gaan nie alleen oor substitusie van objekte nie, maar ook oor die onderlinge verhouding tussen die verskillende objekte. Wat die tuinier vir die takkies is, is God vir die dissipels. Wat die wingerdstok vir die takkies is, is Jesus vir sy dissipels. Op die wyse word 'n metaforiese realiteit geskep wat toeganklik word aan die hand van die verhouding tussen die letterlike en figuurlike wêrelde.

Die patroon van "substitusie" in Johannes 15 kan so voorgestel word:

\begin{tabular}{|c|c|c|c|}
\hline 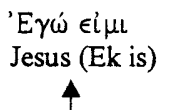 & $\begin{array}{l}\text { ó matíp } \\
\text { Die Vader }\end{array}$ & $\begin{array}{c}\dot{u} \mu \in \hat{\imath} s \\
\text { Julle (dissipels) }\end{array}$ & Figuurlike vlak \\
\hline $\begin{array}{l}\downarrow \\
\text { Wingerdstok } \\
\dot{\eta} a ̊ a r \epsilon \epsilon \lambda o s\end{array}$ & $\begin{array}{c}\downarrow \\
\text { Tuinier } \\
\text { ó } \gamma \in \omega \rho \gamma \text { ós }\end{array}$ & 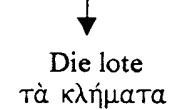 & $\begin{array}{c}\downarrow \\
\text { Letterlike vlak }\end{array}$ \\
\hline
\end{tabular}


Die wyse waarop die letterlike en figuurlike vlakke met mekaar verband hou, vertoon dieselfde patroon in Johannes 15 en Psalm 79 (LXX).

'n Verdere interessantheid is dat woorde soos Egipte, berge, riviere en see in Psalm 79 (LXX) letterlike verwysings is. Egipte is die letterlike plek, maar die wingerd is figuurlik. Op die wyse word letterlike en figuurlike taal vermeng. Daar is ook byvoorbeeld 'n direkte versoek aan God om uit die hemel in te gryp. Hierdie vermenging van letterlike uitdrukkings en figuurlike spraak word ook in Johannes 15 aangetref. In Johannes 15:3 is die "woord" die wyse waarop die gelowiges rein gemaak word, terwyl "gebede", "dissipels wees" en so meer in Johannes 15:7-8 met die beeldmateriaal vermeng word.

\section{METAFORE WAT OP DIE BASIS VAN INTERAKSIE FUNKSIONEER}

Interaksie in Johannes 15 word hoofsaaklik by die gebruik van werkwoorde soos "snoei", "bly in" en "dra" (van vrugte) aangetref. Soos reeds aangetoon is, word hierdie objekte ${ }^{12}$ gesubstiteer ten einde die twee relevante wêrelde (letterlike en figuurlike wêrelde) te identifiseer en met mekaar in verband te bring. Dieselfde werkwoorde word egter beide by die letterlike en figuurlike objekte gebruik en benodig nie substitusie nie. Op die wyse word die twee wêrelde metafories verbind. Byvoorbeeld, in 15:2 snoei die Vader die dissipels net soos die tuinier die takke snoei, en in 15:5 bly die dissipels in Jesus net soos die takke in die wingerdstok bly. Verder moet die dissipels vrugte dra net soos die takke vrugte dra. Dieselfde werkwoord word benut ten opsigte van beide die figuurlike en letterlike vlakke. Die punt van die analogiese, metaforiese oordrag word dan juis in die werkwoord aangetref en dit is ook waar die semantiese oordrag plaasvind.

Hoe vind hierdie semantiese oordrag plaas? Neem 15:5 as voorbeeld

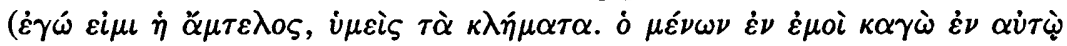

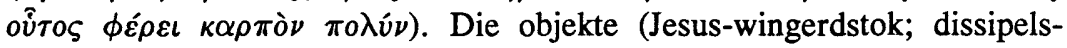
takke) word eers gestel ten einde die raam van die beeldwêreld daar te stel. Binne hierdie raamwerk funksioneer die werkwoord(e) dan. Die werkwoord "bly" ( $\mu \varepsilon \dot{\varepsilon} \omega \nu)^{13}$, oftewel die "fokus"14 van die metafoor, kan beide vir 'n wingerdstok en vir Jesus gebruik word. Takkies kan in 'n wingerdstok bly soos die dissipels in Jesus kan bly. Daar is ' $n$ analogie tussen hoe die takkies in die wingerdstok bly en hoe die dissipels in Jesus bly. 
Hoe werk die analogie? Dit bevat 'n punt van ooreenkoms en juis hierdie punt van ooreenkoms bevat ook die punt van verskil15. Die takkies en die wingerdstok staan in 'n verbondenheid soos die dissipels met Jesus in 'n verbondenheid staan. In die sin van die realiteit van 'n verbondenheid is daar ooreenkoms. Maar die aard van hierdie verbondenhede verskil egter ook radikaal. Die wingerdstok en takkies kan tog nie op dieselfde manier met mekaar in verbondenheid staan as wat die geval met die dissipels en Jesus is nie. Die verbondenheid tussen Jesus en sy dissipels moet dus in terme van hulle verhouding en die moontlikhede daarvan verstaan word ${ }^{16}$.

Skematies kan dit byvoorbeeld so voorgestel word:
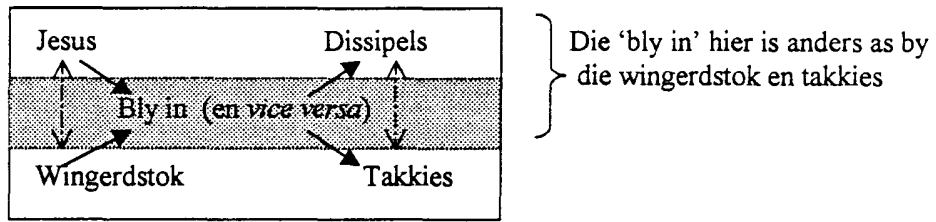

Die wyse waarop die twee tipes metafore (metafoor van substitusie en interaksie) in verhouding tot mekaar gebruik word, moet op gelet word. Die twee tipes metafore word sintagmaties in verhouding tot mekaar gebruik om sodoende 'n saamgestelde metaforiese konstruksie te vorm. Die funksie van die selfstandige naamwoorde is om die letterlike wêreld met die figuurlike te identifiseer, terwyl die analogie tussen die twee vlakke in die metaforiese benutting van die werkwoorde geleë is. Sonder die metafories geïdentifiseerde selfstandige naamwoorde kan die analogiese interaksie ook nie plaasvind nie.

Die twee korresponderende wêrelde word op so wyse in relasie tot mekaar geplaas dat analogiese interaksie resulteer waarin sekere kwaliteite van die een wêreld interaktief vervang en semanties gevorm word deur die kwaliteite van die ander. Wat moontlik en waar ten opsigte van die een wêreld is, is by wyse van analogie moontlik en waar ten opsigte van die ander wêreld. Dit gebeur nie eenvouding met een objek nie, maar met al die objekte wat die hele beeld uitmak. Op die wyse resulteer 'n metaforiese netwerk.

In sy bespreking van die beeld in hoofstuk 10 beklemtoon Schnackenburgi ${ }^{17}$ dat dit juis by die punt van verskil is dat die onderwerp 
verder geneem word soos wat die figuurlike realiteit dit toelaat. Dit geld ook van die beeld in hoofstuk 15. 'n Gewone wingerdstok kan tog nie in die takkie bly en die takkie tegelyk in die wingerdstok nie. Die grense van die letterlike beeld word dus so oorskrei. Die boodskap en realiteit van die figuurlike realiteit bepaal nou verder die vasstelling van die betekenis op die punt van verskil. Presies hoe die dissipel in Jesus bly en Jesus in die dissipel moet vanuit die geestelike realiteit en wat daar geld, beskryf word.

As daar na Psalm 79 (LXX) gekyk word, word soortgelyke metaforiese funksionering aangetref. Die interaksie word ook hoofsaaklik in die werkwoorde gevind. Die wingerdstok word byvoorbeeld geplant (Israel is soos die wingerdstok geplant, maar hoe dit presies gebeur is nie dieselfde nie). Die bos word verniel soos Israel verniel word en beide die wingerdstok en Israel moet opgepas word, maar nie op dieselfde wyse nie. Die werkwoorde funksioneer as interaktiewe metafore. Daar is dus kongruensie en inkongruensie.

Die ooreenkoms tussen die metaforiese gebruik in Johannes 15 en Psalm 79 (LXX) korrespondeer dus. Hoewel die konkrete ontplooing van die wingedstokbeeld verskil tussen Johannes 15 en Psalm 79 (LXX) stem die metaforiese dinamiek funksioneel ooreen.

\section{KLIMAKTIESE BESKRYWING}

As deel van die beeld word daar soms kort vertellings aangetref wat bydra tot die beter verstaan en dramatiese effek van die beeld. Hierdie beskrywings bestaan uit 'n aantal objekte of werkwoorde wat nie individueel gemetaforiseer moet word nie, maar gesamentlik gelees moet word. Interaksie of substitusie vind nie plaas nie, maar die woorde of kort vertelling funksioneer saam ten einde 'n "klimaktiese semantiese atmosfeer" te skep. In hoofstuk 15:6 funksioneer die beskrywing van die afsny van die takke wat eenkant gegooi word en dan verbrand word so. Vier werkwoorde word progressief met behulp van $\kappa \alpha i$ verbind wat beskryf hoe die takke afgesny, versamel en verbrand word. Die werkwoorde funksioneer in kohesie ten einde die dramatiese impak te beskryf van wat dit beteken om so uitgegooi te word $(\dot{\varepsilon} \beta \lambda \dot{\eta} \theta \eta \hat{\varepsilon} \xi \omega)$. Die werkwoorde moet nie individueel geïnterpreteer word nie, maar in verhouding tot mekaar ten einde die korrekte "atmosfeer" te skep" ${ }^{18}$.

In die beeld in Psalm 79 (LXX) speel klimaktiese beskrywing ook 'n belangrike rol. Die verbranding, uittrek, plundering en vernietiging van die wingerdstok moet nie elke individueel gemetaforiseer word asof dit verskillende gebeure wil beskryf nie, maar hulle funksioneer gesamentlik 
om die radikaliteit van die vernietiging te beklemtoon. Die verbygangers en wilde diere vernietig die wingerdstok en die wingerdstok word verbrand. Dit verwys metafories na die vernietiging van Israel, soos wat die laaste paar frases dit ook formuleer: "Die wingerdstok is met vuur verbrand en is opgespit" teenoor "Hulle sal vergaan voor u bestraffing". In die beeld word die verbygangers, die wilde diere en wilde varke nie onderskei nie. Dit gaan nie noodwendig om verskillende volke wat presies benoem hoef te word nie, maar is eenvoudig 'n beeld wat die vyande van Israel funksioneel wil beskryf.

Die figuurlike funskionering van die beeld in Psalm 79 (LXX) en Johannes 15 stem dus ook in die opsig ooreen.

\section{VERGELYKING}

'n Vergelyking verskil van 'n metafoor daarin dat 'n vergelyking die punt wat vergelyk word duidelik formuleer. ("Die vrou is mooi soos 'n roos" teenoor "Die vrou is 'n roos"). In 15:4 word dit gestel dat 'n takkie nie vanself vrugte kan dra nie, maar dat dit in die wingerdstok moet bly. Dit

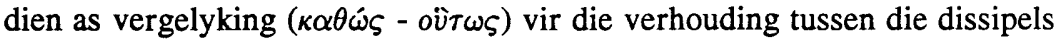
en Jesus. As 'n dissipel nie in Jesus bly nie, akn hy of sy ook nie vrug dra nie. In 15:6 word die vernietiging van die mense wat nie in Jesus bly nie vergelyk met die vernietiging van takkies wat afgesny is. Binne die konteks speel hierdie vergelykings 'n belangrike kommunikatiewe rol. Om soos 'n takkie in ' $n$ wingerdstok te bly is ' $n$ sentraal belangrike punt vir die verhouding tussen Jesus en sy dissipels. Op die wyse funksioneer vergelykings in samehang met metafore ten einde die beeld as geheel daar te stel.

In die gedeelte van Psalm 79 (LXX) waar die wingerdstok ter sprake is, word daar nie van eksplisiete vergelykings gebruik gemaak nie. Dit beteken egter nie dat die skrywer van Psalm 79 (LXX) nie daarmee vertroud was nie. In Psalm 79:2 (LXX) word wel 'n vergelyking aangetref. God word as herder beskryf wat Josef soos 'n kudde lei.

Die figuurlike meganismes wat in Johannes 15 benut word, blyk steeds binne die arsenaal van die skrywer van Psalm 79 (LXX) te lêt19.

\section{KONKLUSIE}

Die resultate van hierdie kort vergelyking is insiggewend, veral as die vraag gevra word na waar die wortels van die metaforiese styl van Johannes lê. Soos reeds vermeld, word daar gewoonlik eerste na die 
Griekse filosowe soos Aristoteles gekyk, aangesien daar lang refleksies oor die aard van metafore gevind word. Tog het hierdie vergelyking met Psalm 79 (LXX) duidelik gewys dat dieselfde dinamiek van metafore in Joodse literatuur voorkom as in Johannes. Op funksionele vlak is daar geen verskil nie. Dit wil dus voorkom of die metaforiese dinamiek van die Johannesevangelie na Joodse wortels teruggevoer kan word, veral as die Joodse aard van die Johannesevangelie self in gedagte gehou word. Die Griekse invloed moet nie oorbeklemtoon word nie ${ }^{20}$.

\section{NOTAS:}

1 C H Dodd, The interpretation of the Fourth Gospel, Cambridge 1978, 137.

2 G Kittel en G Friedrich (eds), The Theological Dictionary of the New Testament, Abridged in One Volume, Michigan 1985, ad loc. beweer: "The image is a common one in the OT, eg, for Israel (Hos 10:1) and the wife (Ps 128:3); it is also used for wisdom (Sir 24:17), and the Messiah (Syr Bar 36ff)".

3 D M Miller, The net of Hephaestus: A study of modern criticism and metaphysical metaphor, Mouton 1971: The Hague, 127, se definisie word as vertrekpunt gebruik. Sien verder I Gräbe, Aspekte van poètiese taalgebruik. Teoretiese verkenning en toepassing, Potchefstroom 1984, 7-102; D Geeraerts, Woordbetekenis. Een overzicht van de lexicale semantiek, Leuven 1986, 49-50; T Reinhart, On understanding poetic metaphor, Poetics 5(1976), 383-402.

4 Sien onder andere W J Jordan, "Aristotle's concept of metaphor in rhetoric" in: $\mathrm{K} \mathrm{V}$ Erickson (ed), Aristotle: The classical heritage of rhetoric, Metuchen N J 1974, 235-250 vir 'n bespreking van Aristoteles se metafoorteorie.

5 Die Johannesevangelie is natuurlik ook 'n Joodse geskrif, maar daar is duidelike Griekse trekke en invloede, wat die moontlikheid van blootstelling aan die Aristoteliaanse metafoorteorieë open.

6 Dit kon in die sewende eeu voor Christus gekomponeer gewees het.

7 Om egter met te fyn onderskeidings te werk maak die beskrywing van die proses te gekompliseerd en is kommunikatief kontraproduktief.

8 "Ingebedde metafoor" word hier verstaan as 'n metafoor waarvan die "tenor" nie direk in die teks benoem word nie, maar waar dit wel uit die teks geïdentifiseer kan word.

9 "Vehicle" is 'n tegniese term wat die tweede deel van 'n metafoor aandui. In "die man is 'n wolf" is "wolf", wat die uitdrukking as figuurlik tipeer, die "vehicle".

10 'n "Gesuspendeerde metafoor" is as die "tenor" van die metafoor glad nie uit die teks self benoem kan word nie. Die "vehicle", wat wel in die teks voorkom, funksioneer duidelik as figuurlik in die konteks.

11 Die Grieks word aangehaal soos dit in die teks na vore tree sodat dit makliker geïdentifiseer kan word.

12 Byvoorbeeld, Jesus - wingerdstok, Vader - tuinier, dissipels - takke, dade vrugte.

$13 \mu \varepsilon ́ \nu \omega \nu$ (bly in) kom dikwels in die Evangelie voor, byvoorbeeld: 1:32, 33, 38, 39; 2:12; 3:36; 4:40; 5:38; 6:27, 56; 7:9; 8:31, 35; 9:41; 10:40; 11:6, 54; 
$12: 24,34,46 ; 14: 10,17,25 ; 19: 31 ; 21: 22,23$, asook in hoofstuk 15 . Sien ook J F O'Grady, “Individualism and Johannine ecclesiology", Biblical Theology Bulletin 5 (1975), 227-261, 243 en K Berger, Im Anfang war Johannes. Datierung und Theologie des vierten Evangeliums, Stuttgart 1997, 200, wat hierdie as die mees sentrale woord in hierdie beeld sien. Sien verder R Borig, Der wahre Weinstock. Untersuchungen zu Jo 15,1-10, München 1967, 19.

14 "Fokus" is 'n tegniese term wat die figuurlike deel van 'n sin aandui.

15 Dit beteken dat "dieselfde" gesien word ten spyte van en deur die verskil. Sien C Koester, Symbolism in the Fourth Gospel. Meaning, Mystery, Community, Minneapolis 1995, 29.

16 D A Carson, The Gospel according to John, Michigan 1991, 516, merk ook op dat die fisiese beeld van die wingerdstok te ver gerek word as daar van die takkies verwag word om in die wingerdstok te bly. Dit vereis 'n aktiwiteit wat verstaanbaar word in die lig van die personifikasie (takkies $=$ dissipels).

17 R Schnackenburg, Das Johannesevangelium, III. Teil, Kommentar zu Kap. 1321, Freiburg 1977, 374.

18 Schnackenburg, $a w, 114$, hanteer die figuurlike aspekte ook met die nodige versigtigheid.

19 Dit verteenwoordig 'n ander lyn as $\mathrm{R}$ Bultmann, Das Evangelium des Johannes, Göttingen 1978, 407-408 wat beweer: “Daß der Weinstock Joh 15 nicht auf die at.lich=jüdische Tradition, sondern auf den Mythos vom Lebensbaum zurückgeht, hat Schweizer 39-41 gezeigt...". Daar is egter genoeg getuienis, soos hierbo aangedui is, dat die beeldmateriaal die Ou-Testamentiese tradisie as interteks het. Sien ook A Thoma, "Das Alte Testament im Johannesevangelium", ZwTh 22 (1879), 171-312. 'n Ander interessante faktor is dat ek nie soortgelyke beelde by die Griekse filosowe, Josefus of Filo kon opspoor nie.

20 Die moontlikheid van universalia moet hier nie uit die oog verloor word nie. Dit mag wees dat hierdie tegnieke eintlik universeel voorkom by groter metafoornetwerke. Dit lê nie op die terrein van hierdie artikel om daardie vraag te beantwoord nie. 